\title{
A Temporary Esophageal Cannula that Prevents Fistula Contraction during Extrusa Collections
}

\author{
K.C. OLSON AND J.C. MALECHEK
}

Abstract

A tubular esophageal cannula was developed for use with cattle during extrusa collections. The purposes of the cannula were to reduce contraction of the fistula while the plug was out and to keep the fistula open to facilitate sample collection. The cannula was made of stainless steel and was attached to the animal by elastic tubing around the neck.

Contraction of fistulae during sample collections is a chronic problem experienced by researchers using animals that are esophageally fistulated (Chapman 1964, Little and Takken 1970, Anderson and Mertz 1982, Walker et al. 1985). The reduction of the fistula diameter makes replacement of a closure plug or cannula difficult for the researcher and painful for the animal. This difficulty can contribute to animal behavioral problems that can compromise the validity of the sampling technique. Modified fistula plugs (Walker et al. 1985), permanent cannulae (Anderson et al. 1985), and surgical procedures (Chapman 1964, Little and Takken 1970) have been developed to overcome this problem. In our experience, these have met with limited success. This paper describes a temporary cannula that is inserted during periods when extrusa is being collected to prevent fistula contraction beyond the diameter of the cannula.

\section{Materials and Methods}

\section{Construction}

The cannula was constructed of thin-wall $(0.05 \mathrm{in}$.) stainless steel tubing and a round plate (about 3 in. diameter by 0.05 in. thickness) with a round hole in the center (about 1.75 in. diameter) welded together in the configuration shown in Figure 1. Thickness

Fig. 1. The esophageal cannula for use during extrusa collections.

of the materials was minimized to reduce weight. Two small rings (about 0.5 in. diameter) were welded on opposite sides of the plate as anchor points for elastic tubing used to encircle the animal's

\footnotetext{
Authors are assistant professor, Fort Hays Branch Agricultural Experiment Station, Hays, Kansas 67601; and head, Range Science Department, Utah State University, Logan 84322. At the time of the research, the senior author was research assistant, Range Science Department, Utah State University.

Utah Agricultural Experiment Station Journal Paper No. 3300.

Manuscript accepted 19 November 1986.
}

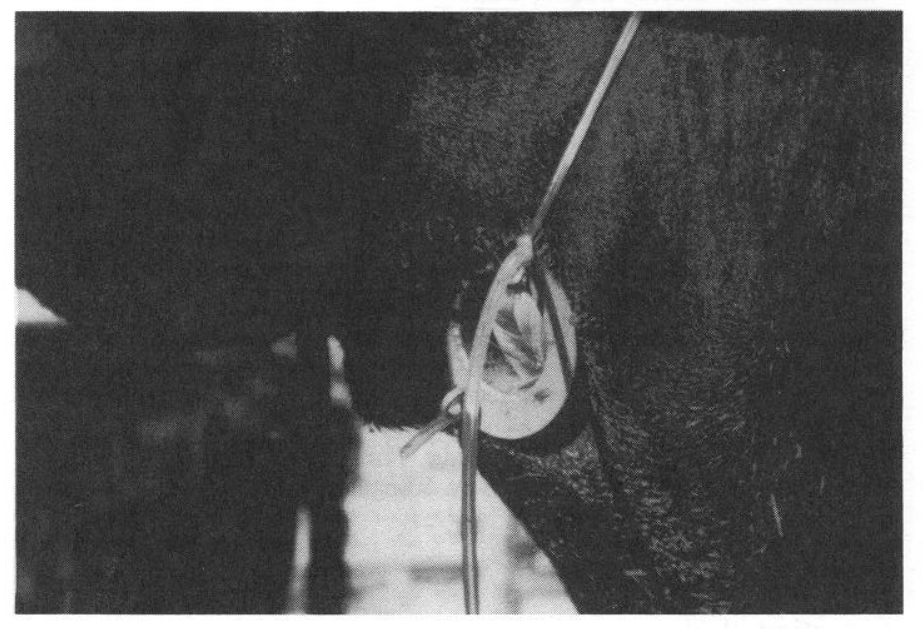

Fig. 2. The cannula in place in the fistula.
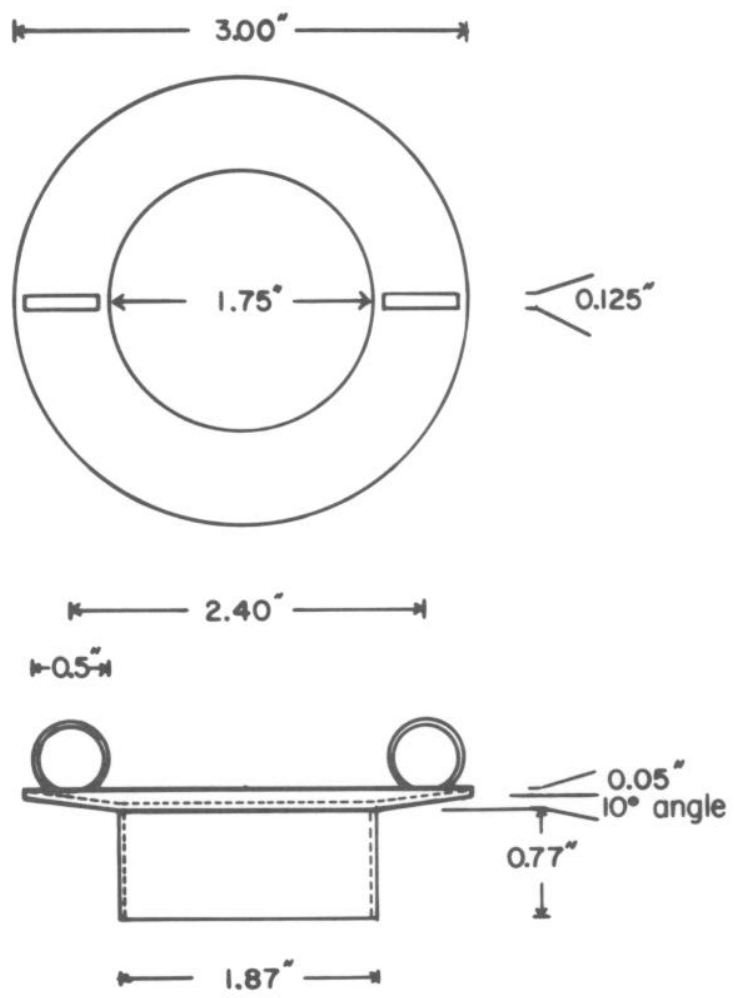

Fig. 3. Top and side views of the esophageal cannula with dimensions appropriate for use in 250-kg yearling cattle. Dimensions are in inches. Dimensions are provided as a guide, and should be adjusted to fit the diameter and depth of the lumen of the actual fistulae, as a function of animal kind, size, and type of fistula plug used. On the side view, the 0.05 in. refers to the thickness of the material used for the plate, and the $10^{\circ}$ refers to the concave angle of the plate (see text). 
neck and hold the cannula in place (Fig. 2). Actual size of the rings was unimportant, as long as the elastic tubing could be readily tied into them. The plate was slightly concave (approximately $10^{\circ}$, Figure 3) to allow a snug fit into the ventral groove of the neck.

A schematic drawing is provided (Fig. 3), with dimensions that we used with cattle. Dimensions are given in inches because the English system of measurement is the standard used by machinists and because stock materials are typically supplied only in English units in the United States. The size described in Figure 3 was appropriate for cattle weighing approximately $250 \mathrm{~kg}$. The dimensions are provided as guidelines, and should be adjusted to meet a specific researcher's needs. They will need to be adjusted for the diameter and thickness of the fistula lumen, as a function of animal size and type of fistula plug used. We used the type of plug described by Denney (1981), but of a size appropriate for cattle. The outside diameter of the steel tubing of the cannula and of the fistula plug should be equal.

The current cost of materials was approximately $\$ 2.50$ per cannula, while labor costs were approximately $\$ 20.00$ per unit.

\section{Attachment}

Immediately prior to attachment of the extrusa collection bag, the steel tubing portion of the cannula was inserted into the lumen of the fistula until the plate portion was snug against the animal's neck. The elastic tubing was then wrapped once around the animal's neck, pulled until it was stretched tight, and tied into the second ring (Fig. 2). Excess elastic tubing was simply allowed to hang in the collection bag. To expedite removal of the cannula following a sample collection, the short end of the elastic tubing was cut at the knot with a sharp pen knife.

\section{Prevention of Fistula Contraction}

The ability of the cannula to prevent fistula contraction was tested with 20 heifers over a 2 -year period ( 10 in each year). Extrusa collections were made with all animals with and without the device to compare amount of contraction under each circumstance. AlI collection periods ranged from 45 to 60 minutes in length. Time required to fill the collection bag determined the length of the collection period. The degree of contraction during the collection period was qualitatively judged by the senior author, and was based on a comparison of the physical effort required to push the plug back into the fistula after collections with and without the cannula. Animal reactions indicating pain or discomfort as the plug was replaced were also observed.

\section{Discussion}

The use of this cannula made a marked improvement in ease of replacing fistula plugs after collections. Fistula contraction occurred to varying degrees with all animals when the cannula was not used. Effort required to replace the fistula plug after collections without the cannula ranged from moderate to extremely hard. Discomfort of the animal was noted in all these cases, with animal reaction ranging from pulling back on the rope to jumping about violently. Use of the cannula essentially eliminated contraction of the fistula. Effort required to replace the fistula plug was minimal, and was the same as if it had only been taken out for a minute or so to inspect the health of the fistula. No signs of animal discomfort were noted.

A second possible benefit from using this cannula is increased probability of making total quantitative collections of extrusa. If a researcher desires to measure bite size or ingestion rate by the methods of Chacon et al. (1976), use of this cannula should help to make the fistula lumen the path of least resistance for boli, potentially eliminating the need for sponge plugs to occlude the esophagus. This would be an advantage because we and others (Jamieson and Hodgson 1979) have noted that sponge plugs create behavioral problems. We did not test the ability of the cannula to improve the probability of making total collections of extrusa.

\section{Literature Cited}

Anderson, D.M., and D.L. Mertz. 1982. An esophageal fistula dilator. J. Range Manage. 35:125-126.

Anderson, D.M., D.L. Mertz, W.E. Franklin, and P.J. Manz. 1545. Improved esophageal fistula closure devices for cattle and sheep. USDAAgr. Res. Serv., ARS-26.

Chacon, E., T.H.Stobbs, and R.L. Sandlend. 1976. Estimation of herbage consumption by grazing cattle by using measurements of eating behavior. J. Brit. Grassl. Soc. 31:81-87.

Chapman, H.W. 1964. Oesophageal fistulation and cannulation in sheep and cattle. Austr. Vet. J. 40:64-66.

Denney, G.D. 1981. A modification of an esophageal fistula plug that allows low maintenance of free-ranging sheep and goats. J. Range Manage. $34: 152-153$.

Jamieson, W.S., and J. Hodgson. 1979. The effects of variation in sward characteristics upon the ingestive behavior and herbage intake of calves and lambs under a continuous stocking management. Grass and For. Sci. 34:273-282.

Little, D.A., and A. Takken. 1970. Preparation of oesophageal fistulae in cattle under local anesthesia. Austr. Vet. J. 46:335-337.

Walker, J.W., J.W.Stuth, R.K. Heitschmidt, and S.L. Dowhower. 1S.s. A new esophageal plug. J. Range Manage. 38:185-187. 